Cad.Est.Ling., Campinas, 53(2): 113-124, Jul./Dez. 2011

\title{
A CIDADE NAS CANÇÕES: SENTIDOS DE PERDA E PERTENCIMENTO
}

\author{
PEDRO DE SOUZA*
}

\author{
"Quando as luzes da cidade se acendem, começa \\ a ronda sem esperança das moças da rua" \\ Jean-Luc Godard - Viver a vida
}

\begin{abstract}
RESUMO: O propósito deste artigo é investigar modos de produzir e significar a cidade a partir de uma modalidade de enunciação em que a voz participa como base discursiva de natureza acústica. Trata-se de modos de dizer que modificam e dão passagem a discursos de cidade colhidos no domínio da canção popular. Delimita a voz e o ato de enunciar cantando como uma das múltiplas modalidades enunciativas que, de dentro de um arquivo de canções, expõem sentido da cidade de que se fala.
\end{abstract}

Palavras-chave: discurso, canção,voz,

RÉSUMÉ: Dans cet article, on analyse les modes de dire la ville à partir de formes d'énonciation dont la voix est le point d' interpellation discursive. L'objet de cette analyse ces sont des l'actes formulations vocales relevés des archives du chant populair brèsilien. On travail sur un recueil de quatre chansons prises comme un aperçu des modalités énonciatives qui montrent le processus de construction subjective de la ville,

Mots-clé: discours, chanson, voix.

\section{INTRODUÇÃO}

Em termos gerais, este trabalho se insere no conjunto de pesquisas cujo pressuposto é o de que não há cidade a não ser como discurso, aí compreendendo todas as conseqüências implicadas na constituição do sujeito urbano (ORLANDI,2004; ORLANDI, 2001). Dessa forma, nada faço senão acrescentar mais um avatar dos já muito estudados lugares de enunciação disponíveis na memória discursiva para que nelas uma urbanidade se estabeleça.

Em termos específicos, minha contribuição visa rastrear configurações discursivas da cidade presentes na canção popular. O que quero é fazer vir à tona, como produto da composição de um corpus e de um procedimento analítico, o aparecimento da cidade como enunciação discursivamente audível no canto popular. Daí a busca de balizas em efeitos enunciativos pontuais, que, na relação com certa ordem discursiva, apontam para a cidade e seu sujeito sendo ditos em certo tempo e espaço.

A discursividade que atravessa o dizer define o movimento dos sentidos da cidade $\mathrm{e}$ do citadino, historicamente situados (ORLANDI,2004). Pode-se assim colher na história

\footnotetext{
* Universidade Federal de Santa Catarina.
} 
as diferentes regiões e eventos enunciativos em que se pode, na perspectiva analítica que aqui pretendo desenvolver, perscrutar, em sua contingência o momento em que uma performance faz acontecer discursivamente uma cidade.

Focalizo o caso de enunciações cancioneiras verificáveis no modo próprio de expressão cultural pertinente à música popular. É como se cada ato enunciativo exercido mediante o canto acontecesse colado a uma memória referida a fragmentos de condições de produção do discurso constituinte da urbe, ao mesmo tempo como objeto e lugar de onde se enuncia. Nesses termos, a cada vez que se escuta uma voz a entoar uma certa canção evocando a cidade, pode-se observar a atualização da memória remetendo a uma já dita urbanidade e subjetividade daí decorrente. Certas peças do cancioneiro popular são exemplares dessa maneira de o discurso acontecer no domínio urbano. Mais adiante vou trabalhar sobre composições que conspiraram a fazer ver, quando não estabelecer, um regime enunciativo para dizer a cidade de São Paulo.

No procedimento analítico proposto aqui recorto precisamente não apenas a textualidade contida na letra da canção. Meu interesse recai sobre o próprio ato vocal que forja maneiras de dizer e historiciza a cidade. Para tanto, lanço a hipótese de que compor e cantar uma canção são gestos extensivos ao que Emile Benveniste (1989a) define como enunciação, isto é, o ato individual de se apropriar das formas da língua.

Benveniste (1989b) deixou claro seu ponto de vista sobre a irredutibilidade entre a semiótica da língua e a semiótica da música. Não é meu propósito refutar a objeção deste autor. Para além do alerta benvenistiano, no contato entre a enunciação falada e enunciação cantada, quero buscar fundamentos para delimitar a vocalização como gesto que põe em funcionamento a canção na qualidade de um peculiar sistema de enunciação, sistema este cujos componentes formais incluem a sobreposição de unidades de estruturação linguística e melódica. Aqui se deve assinalar a aproximação pressuposta entre canção e língua na perspectiva com que Benveniste elabora o conceito de aparelho formal de enunciação, sempre considerando, para fazer valer os termos teóricos da Análise de Discurso, a queda na história a que cada ato vocal de apropriação está sujeito para ser dotado de sentido. A esse propósito é bem oportuna a citação que Murray Schafer (1991, p. 228 faz de Tomás de Aquino : "Onde a palavra cessa começa a canção,(...), na voz."

O que está em relevo nesta afirmação é a musicalidade inerente à língua falada. De minha parte sublinho na mesma citação o dado de que a voz toca e atua algo como o real da enunciação, a saber, o ponto de natureza melódica que antecede a palavra como unidade lingüística. Dito de outro modo, quando se apaga na palavra o vestígio musical que dá lhe origem na voz, o que nela se ressalta são traços sonoros fonologicamente pertinentes, ou seja, os mesmos que fazem dela uma forma da língua apartada das formas da música. Ocorre que ao ser pronunciada na forma da canção, sem deixar de permanecer como unidade da língua, a palavra vocalmente articulada apresenta-se também na forma musical que a constitui e lhe provê da vocação de significar ou de se converter em discurso. Eis o caminho pelo qual abordo a canção como modo lingüística e musicalmente imbricado de fazer sentido.

Amplia-se também a plataforma que Michel Pêcheux (1975) elegeu como a base material do discurso, isto é, o encadeamento sintático e enunciativo. Fica assim valendo não apenas os pontos de ligação entre um termo e outro na cadeia da fala, mas sobretudo 
os pontos vocálicos, consonantais ou entonacionais sobre os quais a voz se detém, prolongando não só o ato de vocalizar, mas também abrindo as possibilidades de fazer sentido. Disso é que se trata na canção ou no contato entre a fala e o canto em um mesmo evento enunciativo $\mathrm{E}$ se esse, pelo ato enunciativo e pela interpelação discursiva, não se faz sem sujeito, tem de ter necessariamente a voz como elemento detonador. Sob esse aspecto, a proposição realça a visão enfatizada por Benveniste. Pelo menos no que toca ao ato de enunciação, o autor sugere que sem realização vocal não há enunciaçãoํ.

\section{A CIDADE QUE SE CANTA NO TEMPO DA PERDA}

Ao me deter na região enunciativa da música popular brasileira, aí recorto uma série de canções que, por alguma razão que me interessa explorar analiticamente, tornam-se o espaço simbólico a dar forma discursiva à cidade de que nelas se fala. Nesses termos, chama atenção o fato de determinadas peças do cancioneiro popular tornarem-se a cançãosimbolo de uma cidade. São composições que não entram no cânone de hinos civis oficiais institucionalmente encomendados para reverenciar um lugar, mas que entretanto ganham mais força que aqueles ao instaurar uma memória.

A questão é saber como, na contingência de seu surgimento, certas canções viram uma espécie de hino-tema de cidade. Essa indagação leva à pedra de toque dos eventos precisos do cancioneiro popular de que passo agora a me ocupar. Para ressaltar analiticamente o modo como, certas canções, fazem ouvir e constituir uma cidade, vou tomar o caso da cidade de São Paulo. A paulistana metrópole acumula, na proximidade de seus quinhentos anos de fundação, uma série de diferentes gêneros de canção cuja escuta dos mínimos acordes adquirem o poder de tornar presente, no tempo em que é entoada e na voz de diferentes cantores, o processo discursivo que a interpela dando lugar ao simbólico da cidade. Tal processo não se dá na linha cronológica do tempo historiográfico, mas sim em séries descontínuas de enunciação que, realizadas no canto, fazem irromper o urbano como acontecimento discursivo.

Nessa referência, insere-se uma sucessão de peças do cancioneiro popular que, a cada vez que são cantadas, fundam uma possibilidade de dizer São Paulo. Refiro-me especificamente a títulos clássicos como Lampião de Gás, Perfil de São Paulo e Ronda. A primeira é uma valsa composta por Zica Bergami (1957) e lançada pela cantora Inezita Barroso em 1958. A segunda, Perfil de São Paulo, é um típico samba exaltação composto por Bezerra de Menezes (1954) e gravada pela primeira vez pelo cantor Silvio Caldas. Quanto à terceira, Ronda, é de autoria de Paulo Vanzolini (1953). Inezita Barroso, três anos antes de gravar Lampião de Gás, foi a primeira a colocar voz neste samba-canção.

Deduz-se aqui uma tríade de composições que trazem a cidade de São Paulo como referência temática do discurso em que se inserem. Ocorre que, a seguir o trajeto sonoro

\footnotetext{
1 "A relação do locutor com a língua determina os caracteres lingüísticos da enunciação. Deve-se considerála como o fato do locutor, que toma a língua por instrumento, e nos caracteres lingüísticos que marcam esta relação. Este grande processo pode ser estudado sob diversos aspectos. (...).(BENVENISTE, 1989a , p. 83).

O mais imediatamente perceptível e o mais direto - embora de um modo geral não seja visto em relação ao fenômeno geral da enunciação - é a realização vocal da língua.(grifo meu).BENVENISTE, Problemas de lingüística Geral II).
} 
que torna visível e audível, a metrópole paulistana em plena emergência na década de 1950, é Lampião de Gás que, a despeito de ter aparecido posteriormente às outras duas canções, converte-se em espaço simbólico primeiro para fazer entrar na história o sentido de São Paulo como cidade em transição do rural para o urbano. Apropriando-se dos acordes e articulando letra e melodia, a voz de Inezita Barroso indicia a posição enunciativa em que se constitui o sujeito deslocando-se da referência urbana que não reconhece no presente. Em outros termos, nos versos e na linha melódica desta valsa produz-se o sentido que vem pela invocação de algo que só se faz atualizar como passado. Trata-se do efeito de discurso acoplado ao ato de enunciar sob a égide da memória que se apaga com a retirada dos objetos simbolizantes da cidade. No andamento pendular de motivação saudosista, percebe-se como o /às/ de 'lampião de gás' rimando sonora e circularmente com 'traz', na estrutura do refrão, fazem desaparecer os objetos que designam na mesma medida em que evolui a melodia da canção.

\begin{tabular}{|l|l|}
\hline Lampião de Gás & Perfil de São Paulo \\
Zica Bérgami & Bezerra de Menezes \\
& Aonde estão teus sobrados, \\
Lampião de gás & De longos telhados, \\
Lampião de gás & E teus lampiões? \\
Quanta saudade & E os moços da academia, \\
Você me traz & Na noite tão fria, \\
& Cantando canções? \\
Da sua luzinha verde azulada & E sinhazinha delgada, \\
Que iluminava a minha janela & Pisando a calçada, \\
Do almofadinha lá na calçada & Na tarde vazia? \\
Palheta branca, calça apertada & \\
& O tempo tudo mudou, \\
Do bilboquê, do diabolô & Mas não apagou, \\
Me dá foguinho, vai no vizinho & A tua poesia.Não mudou, \\
De pular corda, brincar de roda & \\
De benjamim, jagunçu e chiquinho & Não se apagou, \\
Lampião de gás & A tua sedução, \\
Lampião de gás & A garoa, \\
Quanta saudade & Cai atoa, \\
Você me traz & Pra guardar, \\
Do bonde aberto, do carvoeiro & A tradição. \\
Do vossoureiro, com seu pregão & São Paulo num só minuto, \\
Da vovózinha, muito branquinha & É o Brás, Tietê, viaduto, \\
Fazendo roscas, sequilhos e pão & Barracas de flores, \\
Da garoinha fria, fininha & E a multidão. \\
Escorregando pela vidraça & \\
Do sabugueiro grande e cheiroso & Os Pardais, \\
Lá no quintal da rua da graça & Em madrigais, \\
Lampião de gás & O sol rasgando a cerração, \\
Lampião de gás & E a noite com seus pintores, \\
Quanta saudade & Apagando, acendendo em cores, \\
Você me traz & Teu nome, no meu coração... \\
Letra extraída do site www.musicasantigas.mus.bra & Teu nome, no meu coração.. \\
\hline & \\
\hline 6 & Letra extraída do site www.musicasantigas.mus.br \\
\hline
\end{tabular}


Postas lado a lado, Lampião de Gás e Perfil de São Pulo, independente de esta ter vindo pouco antes da outra e de terem sido simultaneamente enunciadas em diferentes vozeados radiofônicos, devem ser inseridas na mesma série de composição discursiva de uma territorialidade urbana. O ponto posicional da formação discursiva em que ambas se fazem enunciar é o que deve e pode ser dito sobre a cidade em expansão econômica. Só que, conforme aponto logo adiante, no mesmo lugar discursivo em que uma lamenta, outra exalta em gesto deslizante o que induz o discurso constituinte da pujança. Há aí uma relação de não coincidência em que o sentido de cidade dito em Perfil de São Paulo na sua diferença é constitutivo do outro dito em Lampião de gás. Para nesta dizer "Da sua luzinha verde azulada/Que iluminava a minha janela" a voz deve evocar de trás de si o cenário desaparecido que a outra apontara: "Aonde estão teus sobrados,/De longos telhados,/E teus lampiões?" Faço aqui menção ao jogo metafórico proposto por Michel Pêcheux(1969). A diferença e repetição são traços da urbanidade emergente que aproximam as duas peças musicais em um mesmo espaço discursivo.

\section{CANTAR DA CIDADE A QUE NÃO SE PERTENCE}

Vê-se que a análise que se esboça até este ponto não deixa de lado a formulação lingüística que estrutura a letra de cada uma das melodias em foco. Mas é preciso realçar a tonalidade que as respectivas partituras musicais induzem para realização vocal. Certamente, a canção resulta de um conjunto de sons servindo de base a uma linha melódica de harmonização que a define em sua singularidade. Esse é o dado específico pertinente a uma análise da composição musical. O que importa, porém, nesta análise, é atentar para a complexidade de sons lingüísticos e musicais em termos de efeito de enunciação. Neles se assenta a base material pela qual a voz enuncia a tônica do que discursivamente se constitui no ato de cantar: o sujeito e a cidade. Em Lampião de gás, lamento e perda não advêm só pelas palavras encadeadas em seus respectivos sentidos dados em língua, mas sobretudo pela tônica a que deve submeter-se a voz para soar em uma sonoridade que vem de outrora apagando o presente em que a cidade é colocada em discurso.

De sua parte, ao ser posta em relação com Lampião de Gás, vê-se de que maneira Perfil de São Paulo funciona deslocando sentidos a vir no mesmo referencial discursivo que faz ver e dizer exuberância urbana. Neste regime discursivo afinado à sonoridade paulistana dos anos de 1950, a cidade emerge na enunciação cantada pairando soberana sobre a voz que a canta. Para que assim o dizer faça uma urbana ambiência, é necessário que a voz seja colocada no percurso acústico que vai da garganta à cabeça até soar fora do corpo do indivíduo cantante. A seguir essa razão analítica, nada mais adequado do que um naipe vocal próximo ao tenor como a voz de Silvio Caldas para tornar audível, em sua propriedade ufanante, a criação de Bezerra de Menezes. Não se trata apenas de técnica corporal mas de simbolicamente fazer valer não mais quem fala, como se faz em Lampião de gás, mas o que é falado, a saber, a cidade.

Tal é o efeito de exaltação resultante do ato vocal interpelado pela mesma discursividade da grandeza, do ufanismo. As canções em foco, cada uma a sua maneira de dizer e de cantar, permitem dar constituição a São Paulo pelo que há de discurso da 
pujança. A diferença é que, em dissonância com o tom afirmativo da grandeza, em Lampião de gás a voz se liga na partitura retirando dela os elementos formais de enunciação cancioneira para gerar aí lamento, não exaltação.

Quanto à Ronda, ela é contemporânea a Lampião de Gás e Perfil de São Paulo apenas no período de sua criação e lançamento por Inezita Barroso. Só vinte anos depois de sua primeira gravação, a obra de Paulo Vanzolini vem juntar-se às sonoridades musicais que conspiram para dizer a cidade paulistana. O caso é que a composição de Vanzolini precisou esperar os anos de 1970, para que a voz da então recém surgida cantora Márcia tornasse audível não o desencanto da mulher em íntima diligência noturna á procura do amado. Passa-se do discurso amoroso para certa edição discursiva em que a cidade paulistana é posta em questão como objeto rondado.

Dessa maneira, as condições de produção são outras para que Ronda passe a compor nova seriação na ordem discursiva da urbanidade paulistana. O tempo da escuta deste hino-simbolo anacrônico, posto que deslocado do tempo de seu aparecimento, e votado a São Paulo, coincide com a plena vigência do regime de ditadura militar e das resistências políticas que coincidem com a afirmação do que se catalogaria como música popular brasileira (MPB). Daí que não se pode cantar e ouvir Ronda sem de alguma forma posicionarse dentro ou no limite do regime ditatorial.

Tem-se aqui mais uma indicação de que a lógica da historicidade não obedece a linha cronológica da historiografia, e sim o ocasionalismo das relações de força em curso. Aí reside um traço importante do modo de enunciar, ou seja, a vocalização musical interpelada pela ordem de discurso. A partir de certo a priori discursivo, a voz deve preceder e suceder a partitura melódica da canção. No limite do ideológico, esse gesto pode não só conformar o submetimento, mas também a resistência: Dito desta forma, genealogicamente Ronda passa em certo instante a configurar o fio do novelo de uma nova série discursiva a propiciar modos outros de dizer a cidade.

Juntemos ao arquivo, que minha análise vem indiciando até aqui, a voz de Caetano Veloso entoando Sampa (1978), no rastro da melodia de Ronda. O que a criação de Veloso produz é algo para além da citação ou da operação intertextual. Em verdade a relação entre as duas composições musicais é antes de tudo de natureza interdiscursiva, isto é, o cruzamento entre as duas acontece no modo com que, na síntese de suas codas, conduzem a interpretar a cidade. Uma, a de Vanzolini, fixa a cidade no horizonte discursivo da violência urbana - cenas de sangue num bar da avenida São João. A outra, a de Veloso, embaralha os contornos do espaço urbano escancarando o efeito subjetivo destituído de centralidade e transbordando pura exterioridade. O que se diz sobre a cidade no samba-canção Sampa se o faz do lado do fora e na falta de qualquer simbólico que a possa constituir: "o avesso do avesso do avesso do avesso".

Ressalto ainda, na análise que desenvolvo, o movimento a que a voz é levada ao entoar as últimas linhas de cada verso. Depois de todos os tons por onde andou ao longo da canção, nota-se o esforço vocal de retornar ao sem lugar de si mesmo. O ritornello torna-se, em verdade, o espaço vazio subsumido pelo que a cidade já significa em discurso. Tome-se, por exemplo, a última frase melódica: "E novos baianos te podem curtir numa boa". Que importa de onde se fala? É desistindo de encontrar o nicho próprio da enunciação e se posicionando do lado de fora que algo é possível dizer sobre a cidade. Em outras 
palavras, trata-se mais da vaguidez locativa de quem enuncia que do nome e do sentido do espaço urbano em que tem lugar a enunciação.

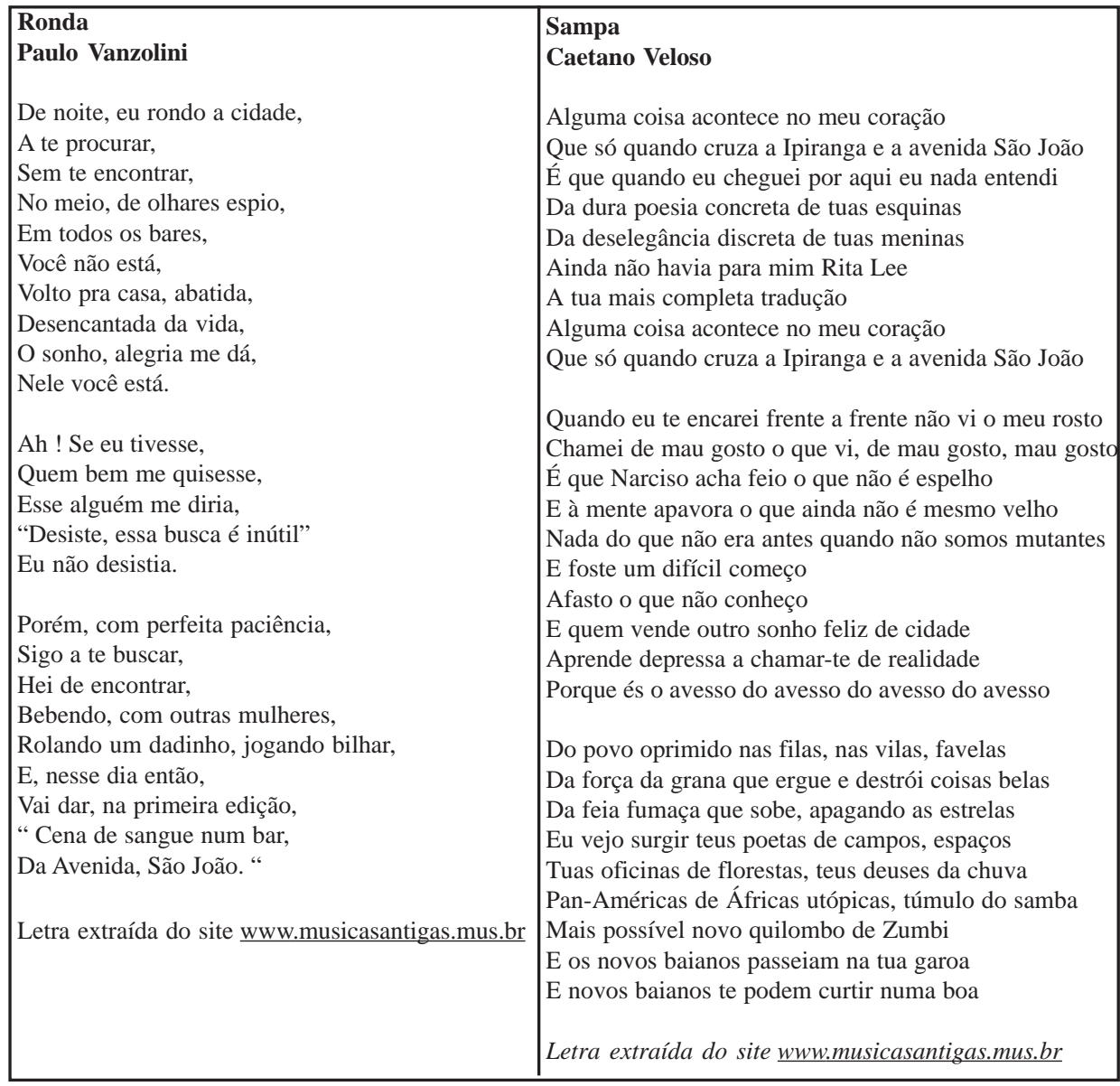

No momento em que Sampa começa a se propagar sonoramente por todos os cantos da cidade paulistana, Ronda já se dá aos ouvidos como dêixis sonora da cidade de São Paulo. A canção de Caetano Veloso passa a figurar então como novo emblema de que o citadino se apodera para cantar o lugar em que se subjetiva urbanamente. Pode ser que, para os ouvidos mais atentos, seja impossível não perceber em Sampa o mesmo compasso e andamento sub-reptício à linha melódica que é própria da canção de Paulo Vanzolini. Por outro lado, em Sampa, os vestígios do já-dito desencadeiam sentidos que ficam a dizer. Contra o melódico da letra de Paulo Vanzolini marcando a familiaridade entre quem fala e o espaço de onde solta a voz em atalaia, joga o vozear de Sampa.

Aqui o jogo metafórico acontece na voz que soa de modo polifônico em Sampa e de modo monofônico em Ronda. O sentido de pertença, próprio do sujeito que vela sobre algum espaço em sua ronda amorosa, desliza em Sampa, dando voz ao que está destituído 
de pertencimento e capturado pelo sentido de estranheza e desconhecimento, conforme mostro adiante.

Observemos a monofonia que se escuta em Ronda. A voz induzida pela partitura do samba-canção obedece, através da linha melódica e do encadeamento rimado das palavras, um trajeto em que o corpo da cidade se faz um com o do cantante. Desenhando um movimento circular, a fonte da enunciação mantém-se como o ponto de onde se parte e se chega. Note-se que Ronda é composta em três estrofes com a indicação de uma pausa no andamento rítmico e narrativo entre a primeira e a segunda:

\begin{tabular}{|c|c|c|}
\hline Primeiro andamento & Pausa & $\begin{array}{l}\text { Retomada do primeiro } \\
\text { andamento }\end{array}$ \\
\hline $\begin{array}{l}\text { De noite, eu rondo a cidade, } \\
\text { A te procurar, } \\
\text { Sem te encontrar, } \\
\text { No meio, de olhares espio, } \\
\text { Em todos os bares, } \\
\text { Você não está, } \\
\text { Volto pra casa, abatida, } \\
\text { Desencantada da vida, } \\
\text { O sonho, alegria me dá, } \\
\text { Nele você está.. }\end{array}$ & $\begin{array}{l}\text { Ah ! Se eu tivesse, } \\
\text { Quem bem me quisesse, } \\
\text { Esse alguém me diria, } \\
\text { "Desiste, essa busca é inútil" } \\
\text { Eu não desistia }\end{array}$ & $\begin{array}{l}\text { Porém, com perfeita } \\
\text { paciência, } \\
\text { Sigo a te buscar, } \\
\text { Hei de encontrar, } \\
\text { Bebendo, com outras } \\
\text { mulheres, } \\
\text { Rolando um dadinho, } \\
\text { jogando bilhar, } \\
\text { E, nesse dia então, } \\
\text { Vai dar, na primeira edição," } \\
\text { Cena de sangue num bar, } \\
\text { Da Avenida, São João". }\end{array}$ \\
\hline
\end{tabular}

A divisão em três momentos figurada neste quadro expõe a indicação de que o andamento enunciativo estabelecido na primeira estrofe encontra seu intervalo na segunda. Isso se comprova logo após o último verso que compõe essa pausa. A frase que introduz a terceira estrofe - "Porém com perfeita paciência" - é uma retomada melódica e rítmica da primeira linha da primeira estrofe - "De noite eu rondo a cidade".

Todo esse esquema soa óbvio quando colocado na perspectiva da criação cancionista. Mas para a consideração do processo enunciativo a ser tomado no âmbito do cantar, a evidência desparece e há que se observar o que se opera na voz, tal como vem predefinida na partitura. Na letra e na melodia os sentidos de permanência e pertencimento subjetivo sobrevêm da referência espacial dêitica dada como ponto de ancoragem da ressonância vocal. Seja no desencontro - Sem te encontrar - , seja no encontro - Hei de encontrar -, a voz soa sempre no aqui da enunciação rondante. É como se uma só coordenada enunciante se deixasse tomar por um vozear cujo efeito de sentido já está desde antes previsto. Visto desta maneira, a voz no corpo de quem o articula serve-se simbolicamente da cidade como a plataforma enunciativa, a mesma de onde perfila o sujeito. Se o sujeito da enunciação é assim co-extensivo ao lugar em que fala, é porque, no vai e vem da ronda, há um dizer que a precede garantindo a cidade como espaço fixado de efeitos de sentido.

O que do discurso amoroso em Ronda remete-se ao discurso urbano? Sob as condições discursivas da violência, na enunciação armada como palco do melodrama, uma cidade se constrói. O enunciado-tipo da imprensa do fait-divers entra no último verso indiciando exterior e colateralmente a dominante discursiva que aí deve funcionar: " Cena de sangue 
num bar/Da Avenida São João”. Este é o ponto do encadeamento melódico em que a voz faz uma intensa e prolongada inflexão deixando nela colidir o dizer do amado nunca encontrado com o dizer da violência constitutiva da cidade. Vemos aí o trabalho analítico mostrando como Ronda passa do sentido da dor de cotovelo com que foi escutada nos anos de 1950, ao sentido emblemático de uma metrópole violentamente emergindo na década de 1970.

Na canção de Veloso outra sonoridade urbana se escuta. O nomadismo do sujeito se produz na voz submetida ao ritmo vertiginoso desta passagem : "E à mente apavora o que ainda não é mesmo velho/Nada do que não era antes/ quando não somos mutantes". Os versos ressoam deslizando para fora do espaço simbólico da dita urbanidade em constante transição.

A métrica e o tempo alongado dos versos que precedem as duas últimas frases de cada estrofe determinam um vozear em que a extensão da frase é muito maior que o tempo para aspirar e expelir o ar durante a emissão. Mas o momento mais forte em que está na música o espectro de um virtuosismo vocal não importa quem seja o cantor. A voz soa sob o custo de ficar a beira de perder o controle da respiração sem sair da melodia. Seja em andamento mais lento ou mais veloz, em tonalidades mais altas ou mais baixas, um virtuosismo vocal qualquer - do agudo discreto de Caetano Veloso ao sussurro bossanovista de João Gilberto, algo na voz, articulada a beira de perder o controle do fôlego, se produz como sonidos tribais tocando o real ou o não-sentido da cidade.

$\sqrt{ }$ Pan-Américas de Áfricas utópicas, túmulo do samba mais possível novo quilombo de Zumbi

$\sqrt{ }$ E novos baianos passeiam na sua garoa

Este é o ponto mais emblemático do encadeamento que acontecera no final das outras estrofes. A frase é longa demais para compor um único verso. O que se percebe aos ouvidos mais atentos é um ajuntamento de sílabas quase que mimetizando o movimento vertiginoso de corpos que vão se amontoando. Mas para soar dentro do ritmo e da melodia a voz deixa embalar-se por batidas que harmonizam notas musicais com grupos acentuais tônicos e átonos. As proparoxítonas em américas, áfricas, utópicas,túmulos localizam sucedem às paroxítonas dos conglomerados vocabulares como do-samba, mais-possivel, novo quilombo até interromper-se na oxitona de Zumbi.

Aqui o imbricamento das unidades acentuais retira a percepção das marcações de divisão silábica e vocabular. O início do segundo acontece como continuação da mesma frase que lhe antecede, mas prosodicamente é emitida depois de breve pausa a partir da qual muda-se o andamento da melodia. O dizer que se fazia de um só fôlego passa da vertigem ao ritmo constativo de quem apenas contempla o que se passa fora de si: $E$ novos baianos passeiam na sua garoa ...

Essa entonação híbrida de prosódia linguística e musicalidade é que faz com que de um único, frenético e alongado sopro vocal, escutem-se vozes superiores e inferiores, soberanas e subeterrâneas, cada qual enunciando em sua cinesia própria o acontecimento do drama do sujeito que se constitui na cidade como o que nunca chegou a pertencer. É quando no ponto de mudança de tessitura se diz «E os novos baianos.. ». Aí, ao longo da canção, como que em uma cena ritualística de inspiração tribal africana ou indígena, o 
que se delineia é a vocalidade que dança em uma discursivade pobre de provimento subjetivo.- «É que narciso acha feio o que não é espelho... »

Ao transitar a tonalidade vocal, um movimento de fuga e retorno se faz sentir. $\mathrm{O}$ modo de emitir que é constitutivo da estrutura melódica da frase produz o efeito sonoro de batidas de percussão. O ritmo e a velocidade desse momento intensivo da canção evoca $o$ que José Miguel Wisnik (2004) associaria às sonoridades tribais africanas. Isso que se repete a cada final de estrofe abre espaço para a heterogeneidade e incompletude dos sentidos de cidade.

Enfim o que se desencadeia ao longo das linhas de cada estrofe é a presentificação simultânea de múltiplas vozes que disparam ritmicamente um pouco antes dos versos conclusivos. As duas últimas frases em cada estrofe, ponto de retomada da frequiência respiratória, arremata polifonicamente cada uma das três partes da composição de Sampa. $\mathrm{O}$ andamento lento encaminhando para a conclusão passa a enfatizar mais a dimensão melodiosa provendo ao discurso a posição enunciativa em que a cidade se constitui e diz pelo que a ela não pertença.

\footnotetext{
$\sqrt{ }$ Que só quando cruza a Ipiranga e a Avenida São João

$\sqrt{ }$ Porque és o avesso do avesso do avesso do avesso

$\sqrt{ }$ E novos baianos te podem curtir numa boa.
}

A polifonia que se supõe e que se escuta na tessitura de cada um desses enunciados finais não diz respeito apenas ao que Osvald Ducrot (1987) estabeleceu conceitualmente como várias perspectivas ou posições encadeadas em uma mesma sequência enunciativa. O som que advém da escrita musical conspira para enunciar o sentido da perda referencial com relação à cidade que se nomeia. É preciso abrir as orelhas ainda mais para escutar, além do que pode estar sendo dito na letra da canção, a tessitura com que se faz o desmanche subjetivo ou a derrubada dos referenciais de identificação.

Na trama melódica composta em Sampa, pode-se dizer de um gesto, que, na fronteira do simbólico da cidade, entrelaça vários discursos. Só que se, em Ronda, há uma enunciação vocal produzindo um sujeito mirando - no outro do discurso amoroso que enuncia perdido - o encontro consigo mesmo, em Sampa, as múltiplas vozes evocam e invocam o desencontro no ponto da memória urbana não coincidente com sua atualização. A cidade que se canta é plataforma enunciativa do encontro da diferença e do desencontro do mesmo.

Mas se a criação de Caetano Veloso pode estabelecer com a de Paulo Vanzolini uma certa relação, pode-se dizer que esta, além de intertextualidade, é também de interenunciabilidade : são séries de enunciações cujas respectivas coordenadas de tempo e espaço se cruzam uma no rastro sonoro de outra. É que ao colocar os ouvidos na sonoridade Ronda, retiramos auditivamente daí um quadro enunciativo que se torna muitos quando levados a compor a sonoridade urbana em Sampa. Na canção de Caetano Veloso, escutase a proliferação sonora e rizomática da metrópole. Já em Ronda, ouve-se a ramificação enraizante do som em um só lugar simbólico. A metáfora que vale incluir aqui é a da ronda policial que não visa vigiar os transeuntes, mas guardar o espaço metonimizado naquele que se escolhe seguir. Daí a relação imediata da imagem de cidade como violência de que o samba-canção de Vanzolini passa a ser símbolo em tempos de regime militar. 


\section{CONSIDERAÇÕES FINAIS}

A linha analítica que adotei neste artigo tomou as ficções cancioneiras como pontos de intercessão enunciativa no discurso da e sobre a cidade. Por esta razão, privilegiei, entre tantas, a escolha de quatro canções tão emblemáticas quanto estas que se referem a São Paulo : Lampião de Gás, Perfil de São Paulo, Ronda e Sampa. É importante ressaltar que o que foi desenvolvdido aqui, sobretudo sobre a canção de Caetano Veloso, em nada pretende descondiderar ou substituir a rica e minuciosa análise já realizada por Luiz Tatit (2002) no âmbito da semiótica. O que propus foi explicitar, por outro dipositivo conceitual e analítico, a discursividade, coincidente ou não com a que se verifica nas análises de Tatit, que atravessa o precedimento composional na direção de dispor modos de enunciar a cidade e o sujeito que dela fala.

Da mesma maneira que se pode falar da textualização do discurso (Orlandi, 1996), pensando-se a historicidade, o político, o movimento da significação, não atado aos operadores da coesão e da coerência, pode-se conceber a maneira de fazer e cantar canções como formas do discurso em música. A consequência é que, para a enunciação, o deslocamento demanda a presença do corpo ressoador ou a corporificação do discurso pela voz. Na comparação analítica entre Ronda e Sampa, percebe-se mais claramente como o elemento vocal, tomado não em sua competência musical, mas como parte de um funcionamento discursivo e enunciativo, pode gerar o corpo da cidade. Mesmo que em direção um tanto diversa, Eni Orlandi abriu caminho para esta visada. Assim é que de uma canção a outra o corpo da cidade pode ser convertido em outro (ORLANDI, 2004: p. 119128).

De um jeito ou de outro, é importante que, no domínio do canto popular, a análise aponte que a transformação discursiva a constituir diferentes efeitos de cidade demanda a apropriação de sonoridades por um gesto vocal. Ele pode ser individual ou coletivo, mas sempre soa conspirando movimentos de subjetivação e dessubjetivação contemporâneos ao que se vê, se escuta e se diz como cidade. No campo em que quero inserir esta proposição analítica, ou seja, a que realça a voz como elemento enunciativo inerente, trata-se sempre do ato de enunciar que se estrutura em canções urdidas em meio ou na fronteira das discursividades que as tornam possíveis. O que pretendi avançar é a ideia de um modo de escuta específica em que a voz é o ponto que surpreende, interrompe a obviedade do sentido e da referência, no caso o de cidade, antes que se instale.

\section{REFERÊNCIAS BIBLIOGRÁFICAS}

BENVENISTE, E. (1989 [1970]). O aparelho formal da enunciação. In Problemas de Lingüística Geral II. São Paulo: Pontes. cap. 5, p. 81-92.

. (1989 [1969]). Semiologia da língua. In Problemas de Linguíística Geral II. São Paulo: Pontes. cap. 3,. p. $43-67$

DUCROT, O. (1987). "Esboço de uma teoria polifônica da enunciação" In O dizer e o dito. Trad. Eduardo Guimarães. Campinas, SP: Pontes. P. 161-222

ORLANDI, P. E. (2004). A Cidade dos Sentidos, Campinas,São Paulo: Pontes. 
PÊCHEUX, M. ((1975), 1995). Semântica e Discurso: uma crítica à afirmação do óbvio. Ed. Campinas Ed. Unicamp.

SCHAFER M. (1991). O ouvido pensante. São Paulo: Editora da Unesp.

TATIT, L. (2002). O cancionista. São Paulo: Editora da USP. . (2001). A cidade atravessada, Campinas: Pontes.

WISNIK, J, M. (2004). O som e o sentido: uma outra história das músicas. São Paulo: Companhia das Letras. 